\title{
Realtime monitoring for groundwater level and local climate based on universal communication system
}

\author{
Rony Teguh ${ }^{1}$, Hepryandi Usup ${ }^{2}$ \\ ${ }^{1}$ Department Informatics Engineering, University of Palangka Raya, Indonesia \\ ${ }^{2}$ Department of Mining Engineering, University of Palangka Raya, Indonesia
}

\begin{tabular}{l}
\hline Article Info \\
\hline Article history: \\
Received Sep 14, 2020 \\
Revised Dec 18, 2020 \\
Accepted Feb 17, 2021 \\
\hline
\end{tabular}

\section{Keywords:}

Communication system

Groundwater level

Internet of things

Sensor networks

Tropical peatland

\begin{abstract}
The groundwater level and weather patterns and climate conditions are several of the very significant factors which influence the quality of livelihood and the other activity of the tropical peatland environment. The current method of groundwater level and meteorological information aggregate build the use of certain expensive weather station devices, prominent to a lack of vast monitoring suitable to cost barriers and disturbance in some countries. In this research, we have developed and implemented a hardware module based on an Arduino microcontroller and mobile communication, which measures the groundwater level and meteorological data, including air temperature, air humidity, and soil temperature, and humidity, rainfall in peatland area. The data groundwater level is received by a specially developed application interface running on an Internet of Things (IoT) connected through a Global Mobile System (GSM) communication. In this work, our proposed system is a model system that can able to generate alerts based on the real-time groundwater level and data weather as potential peat fire in Indonesia. It provides online and data real-time monitoring. In this works, we have resulted in a system to monitor the groundwater level and data weather alert, condition mapping, and warn the people from its disastrous effects.
\end{abstract}

This is an open access article under the CC BY-SA license.

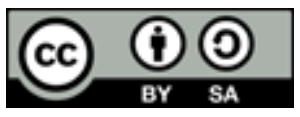

\author{
Corresponding Author: \\ Rony Teguh \\ Department Informatics Engineering \\ University of Palangka Raya \\ Yos Sudarso Street, Palangka, Palangka Raya City, Central Kalimantan 74874, Indonesia \\ Email: ronnyteguh@gmail.com
}

\section{INTRODUCTION}

The groundwater level and data weather and condition of climate are some of the really important factors which influence the quality of livelihood and the other activity of the tropical peatland environment. The current way of groundwater level and data meteorological collection makes use of a high-cost weather station, leading to a drawback of wide monitoring due to cost constraints and inconveniences in certain countries. One of the required terms for the accuracy weather is the gain of precision meteorological data. When the parameter of data meteorological is insufficient, the citizen available information about the prediction of weather would be inaccurate. A tropical peatland forest is one of the most important renewable natural resources that play significant roles in human life and ecology. Typical peat and forest fires are natural disaster phenomena. In recent years, chronic dry weather, quickly expanding exploitation of tropical forests, and the request for the transformation of forest to farmland has become severe with escalate of peat-forest fire size. Tropical peat forest fires are also serious disasters in terms of loss of both property and life. In Central Kalimantan of Indonesia, tropical peat forest fires are mostly anthropocentric. 
The local people and transmigration farmers used fire as an area of small farmland activities such as land clearance. In the dry season, a few fires have spread of uncontrolled and become wildfires to peatland areas. The tropical peat and forest fires not only burn the surface vegetation but also the in-ground of peat deposits more than 100 centimeters under the soil surface. But, tropical peat fire happens only in extremely dry conditions or since the groundwater level has been lowered artificially. Tropical peat fires produce high amounts of gas toxic and deteriorate air quality the the concentration of haze also causes health problems. We can see tropical wildfire have many negative effects on human health, economy, environment, and climate. Tropical peat fire occurs when three necessary conditions are satisfied at the same time flammable material, oxygen, and high temperature. The source of a tropical peat fire in Indonesia is the activities of local farmers such as clearance of land and to make fertilizer from ash. In this paper, in Figure 1, our device for measurement groundwater level (GWL) using an ultrasonic sensor. The sensor installed into the PVC pipe well for measurement of the groundwater level. The ultrasonic sensor is assembling at the end top of the PVC tube. The PVC tube is installed underground peat and its end bottom to touches peat soil. The ultrasonic sensor produces by the electromagnetic wave down in the waveguide tube, is reflected at the water surface, and travels back up to the ultrasonic sensor at the top of the pipe. The propagation wave of use ultrasonic is $40 \mathrm{kHz}$ to measure the groundwater levels in this experiment.

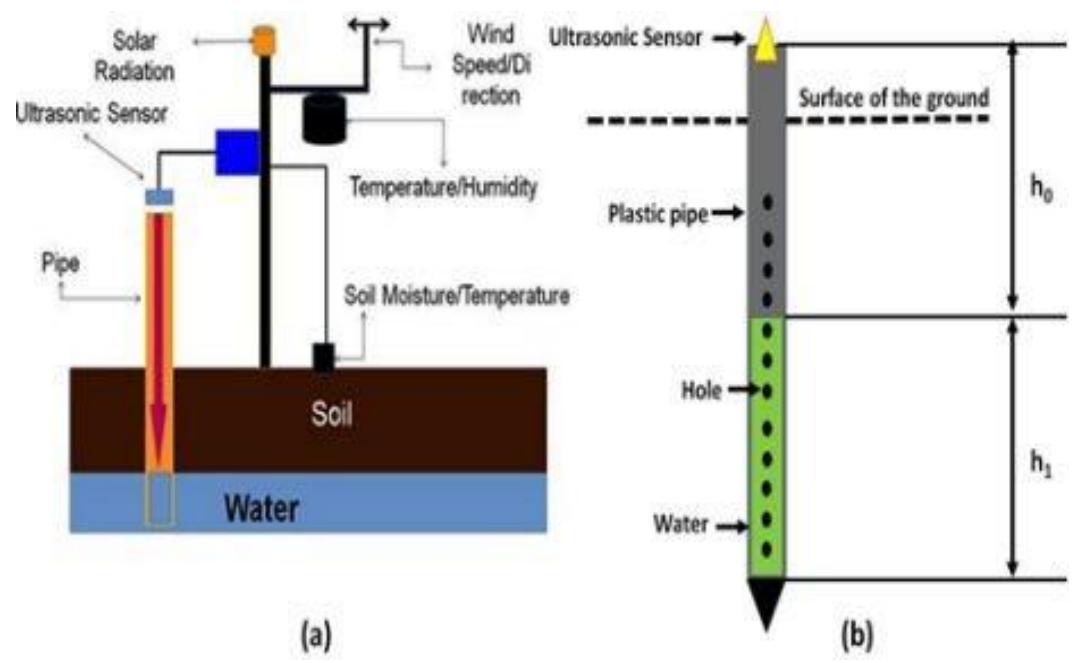

Figure 1. These figures are; (a) Overview ardupeat sensor network, and (b) The well construction for groundwater sensor

In Figure 2, fires in peatland not burn the surface, however also the underground peat. The condition of local weather and groundwater level has a necessary influence on potential peat fire. When the groundwater level drops from 0.5 meters to 1 meter. In this condition is precise to be very dangerous for peat fire.
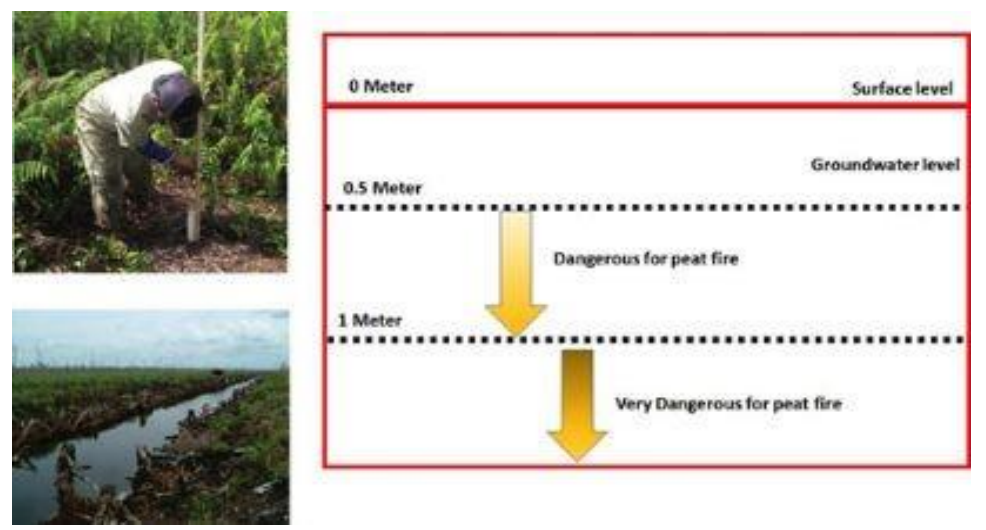

Figure 2. Relation tropical groundwater level with potential peat fire 
In hydrology systems such as groundwater level [1]-[3] and moisture of surface peat are important keys for peat fire-control [4], [5] in tropical peatland. The propagation rate of peat fire on surface peat soil has an ordinary of $42-155 \mathrm{~cm} /$ day and in subsurface peat soil $12-60 \mathrm{~cm}$ day. Flaming needs temperature is more than $500{ }^{\circ} \mathrm{C}$ with a duration of more than 20 minutes. As mentioned above, the peat fire starts with overheating because of weather conditions in peat soil drying [6]. Tropical peat is normally formed from trees, whereas boreal peat is composed of vegetation and grasses. Suitable to their higher calorific values, peat soil matter is over combustion as fuels, especially when the condition peat is dry. Some work has been done in this regard. In [7] the author work with low-power wireless sensor networks (WSNs) to develop remote monitoring wetland hydro chemical dynamics still time scales ranging from decades. All sensor network has multiple devices to monitor groundwater level, precipitation, evapotranspiration, temperature. The WSNs be generated to report data in near real-time by the internet WSNs application toward real-time data aggregated at the freshwater resources such as rivers, lakes, or wetlands areas to acquire exact water quality measuring [8]. Meanwhile, a deployment hydrology monitoring system using the application of ZigBee and GPRS technology is capable to obtain distance hydrology observe such as a river, fishpond, or irrigated area [9]. The sensor network system is used as an embedded platform to surveillance the freshwater quality, deployed at a spread of the location in which each sensor node capable of interface with a few water quality sensors. Hydrological monitoring is an application of ZigBee technology, which has a robust performance value. The author was developed and implemented to monitor the climate-related to global warming in tropical peatlands, Indonesia. The SASAME device is mainly composed of the sensor, the data logger, the data communication module, and the battery system. The author uses the sensors for water depth, moisture tension, and soil subsidence length of circumference was combined with SESAME-II. The device used to the groundwater and ground surface levels in peatlands, in the river and the dam lake, and the irrigation trees in a plantation in Indonesia [10], [11].

The system has effectively useful to the real-time monitoring of the condition of water temperature and level of $\mathrm{pH}$ in an artificial lake. In [12] the author works on developing the design and implementation of a complete WSN that can be used for a space of a long time environmental monitoring using IoT applications. The author work also in many functions of the WSN is respected: the structure of the WSN, optimization of the node sensor and gateway for link communication protocols, self error recovery for the node operation, the server application reliability and interfacing with IoT applications. The author [13] works to integrate IoT method with big data technologies into a holistic approach for real-time data monitoring and processing. Using cloud IoT platforms that enable generate web services appropriate for the integration data on the Internet. The author [14] proposes the development of an application for precision farming using a wireless sensor network with IoT cloud platforms that allow web application and real-time communication data. The author [15] presented the design of new software and hardware of water monitoring which connected in a temporal way to the WSN infrastructures. The author using Zigbee protocol multi-hub data communication for collected data. In this paper, our problem is how to develop for monitoring groundwater level and local peat climate using low-cost sensor technology.

We have study some research in the measurement water level for our work. In the system, we have developed uses ultrasonic sensor measure the water level in the peat soil. We also proposed solutions that easy to use and low-cost using Arduino based. This system a usefull solution for monitoring and peat fire early warning systems with indicator groundwater level in peat is very lower and soil moisture is drying. In our system of groundwater and weather monitoring, the environmental data are sent to a computer-based system through an Arduino board. The many data parameters are simultaneous transmission and finally the process by an only single channel to show the data on the computer. For collect and record of the data, the stream of data taken by the sensors is collected in the Internet of Things (IoT) [16], [17] based on the system which communicates through global mobile system data transmission. Our contribution of this paper is the design, construction, and implementation of a distributed in-field groundwater level and weather station based on an Arduino and the Internet of Things (IoT) in peatland. The device has been designed with usefull and effective to several peatland parameters such as ultrasonic distance for the watertable, temperature, humidity, soil temperature, moisture, and all data realtime send to the internet by a global communication system.

\section{RESEACH METHOD}

\subsection{Study site}

In this work, we placement Ardupeat sensor into the experimental field for demonstrating the working of the system and the groundwater level measurements as shown in Figure 3. The locate device installation near the small forest campus of Palangka Raya University by a depth of peat soil is 0.5 meters. The length of the PVC pipe used in this implmentation is 1 meter. We get the sampling data from 28 September - 4 October 2019 in dry condition. The sensor data record every 15 minute and directly send to database server by TCP/IP protocol. The ArduPeat sensor for monitoring and automating the hydrology of the peatland area, Arduino 
mega modules in the configuration were used. They were packaged on a PVC case with external connectors for types of equipment and communications. The Arduino microcontroller is used for storing data in a microSD memory, it is also in charge of microclimatic data acquisition, global mobile system communication. The devices used in the implementation can be appreciated in the connection diagram in Figure 4.

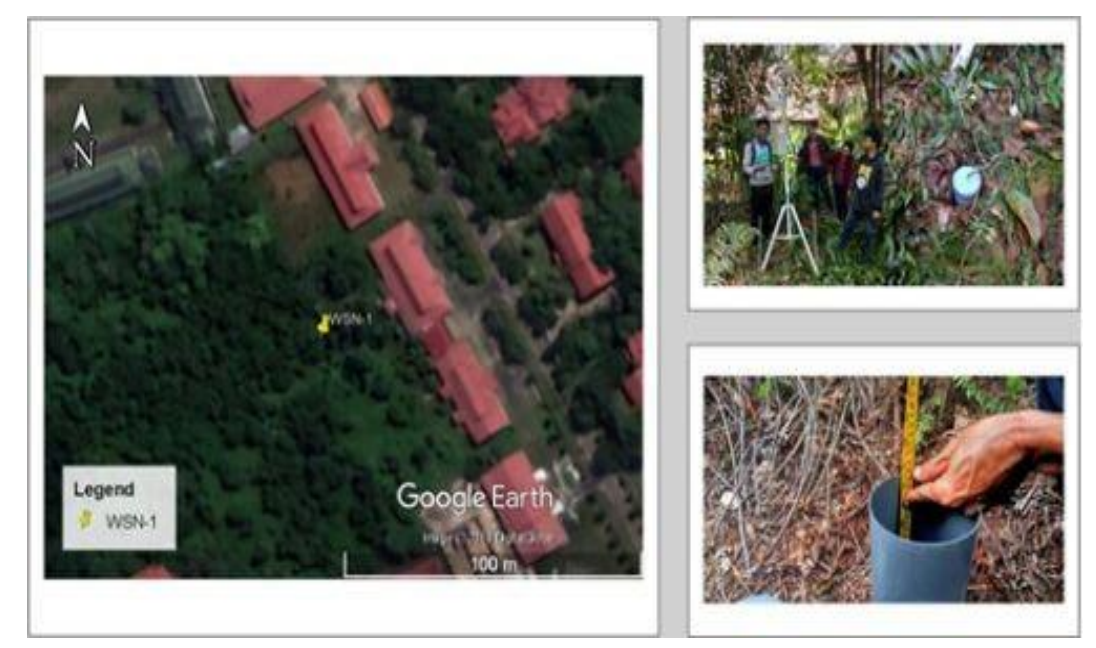

Figure 3. Placement and installation ardupeat

\subsection{The architecture ardupeat system groundwater level monitoring}

In Figure 4, our system is especially to build a software development platform and design embedded in the sensor node. The Ardupeat uses 4-layer methods: sensor layer, communication layer, a layer of the internet of things, and the user layer. The communication layer based on the GPRS module library, in addition, to obtaining the kernel in the operating system operates the GPRS module to activation the global mobile system layer. The internet of things layer based on a cloud system based on Linux OS with a visualization of the data. The edge of the layer is the user layer based on the above several layers which correspond to the certain applications of hydrology and climate monitoring systems establish various duty that uses the data visualization and interface.

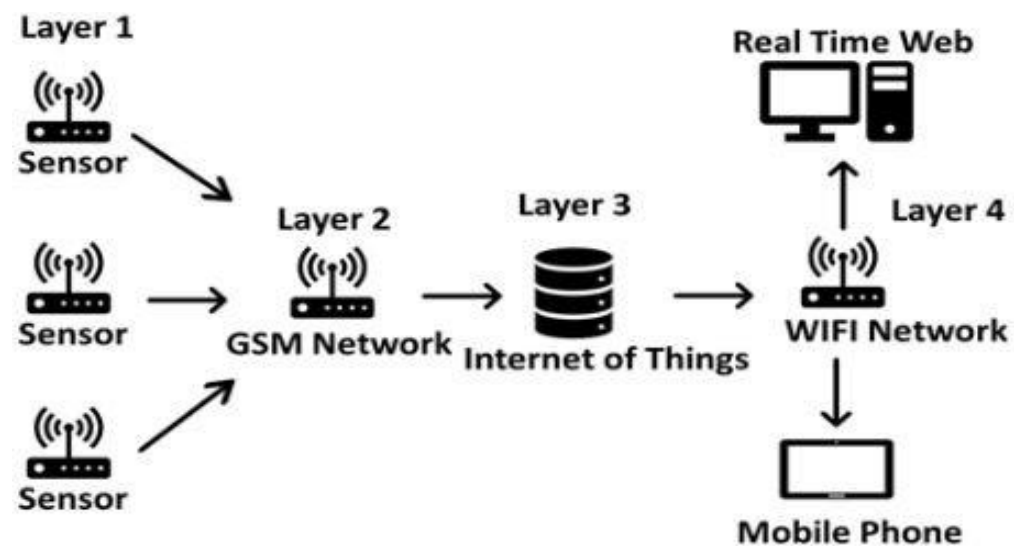

Figure 4. The overview architecture ardupeat system groundwater level monitoring

\subsection{Ardupeat hardware}

The proposed hardware system of ArduPeat sensor network is shown in Figure 4. Our system is consisted by the following three parts. 


\subsubsection{Communication data}

The hydrology data collect and direct send using the GSM network is transmitted to the data receiving cloud. The database over the Internet by GPRS/3G [18], [19], to perform long-distance data transmission. In this work, we use AT command delivery data using TCP/IP protocol to the internet cloud network.

\subsubsection{Component of sensor}

The groundwater level using ultrasonic sensor for measurement of distance [20]. The sensor operation voltage on $5 \mathrm{~V} \mathrm{DC}$, operation range $25 \mathrm{Cm}$ to $4.5 \mathrm{~m}$ with resolution $0.5 \mathrm{~cm}$. Ultrasonic installation on the top of pipe. A pipe modification with point every side with distance $5 \mathrm{Cm}$ (see Figure $2 \mathrm{~b}$ ). The station including air temperature, humidity, soil moisture, soil temperature, rain gauge [21], [22]. In the Table 1, shown component sensor and function use for our works.

\subsubsection{Power of source}

Power of source. To optimal Ardupeat device, the performance of energy power the battery shall able to power the full system for at least 24 hours, without any recharge, and the solar panel must be smart to charge throughout on the day the energy consumed overnight [23], [24]. The ardupeat has requirements for the energy battery and the solar panel [25] was determined as $10 \mathrm{Ah}$ and $12 \mathrm{~V}, 1.2 \mathrm{Amp}$ respectively.

Table 1. Component sensor and function

\begin{tabular}{lll}
\hline Component & Description & Function \\
\hline Arduino Mega & Microcontroller board & Manage, arrange and transmissit data \\
DHT22 & Temperature and Humidity sensor & Record air temperature and humidity \\
SIM900 & GPRS/3G Module & Internet communication \\
Solar Power Manager & Solar Controller & Power \\
DS18B20 & Soil Temperature & Record soil temperature \\
FC-28 & Soil Humidity & Record soil humidity \\
4-20HR-MaxSonar & Ultrasonic sensor & Record distance \\
WS-1080 & Rain gauge & Record rain \\
\hline
\end{tabular}

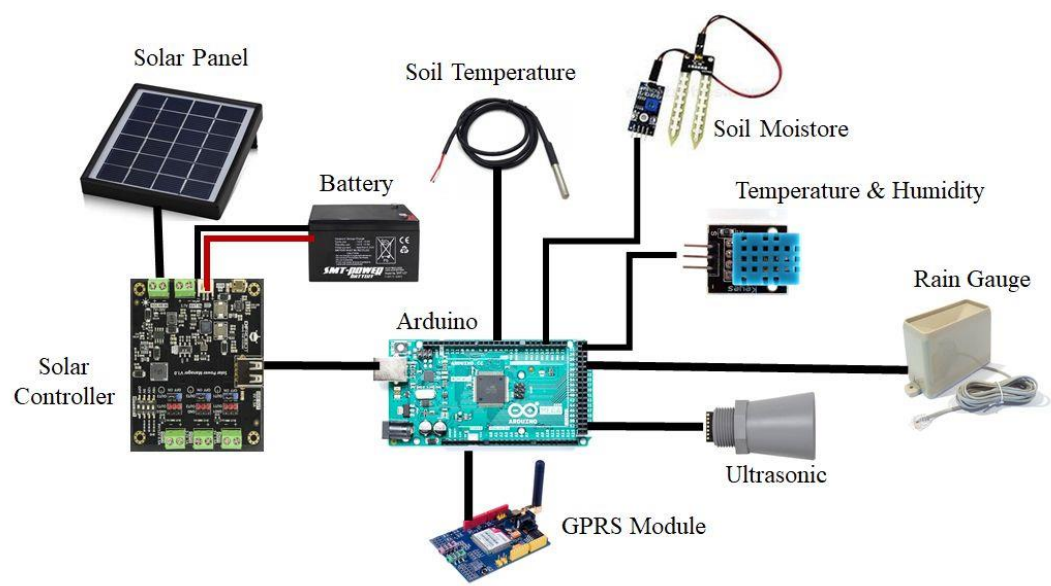

Figure 5. The sensor component of ardupeat

\subsection{Ardupeat software}

In this work, we propose software design for ardupeat sensor network. We develop an application for component sensor and data communication using the Arduino programming languageFrom the sensor, this software can record stream the data acquisition and directly send use the internet uses hypertext transfer protocol (HTTP). After the data from the sensor was uploaded from the Ardupeat connected to a GPRS/3G module to the cloud server. All updates the data record from the sensors and distribution the parameter in graph to the users. In this work, the features of the software the user requirement to create every account and dynamic IP address that contains the different for monitoring the different data records in the system. The flowchart diagram of the ardupeat system is shown in Figure 6. 


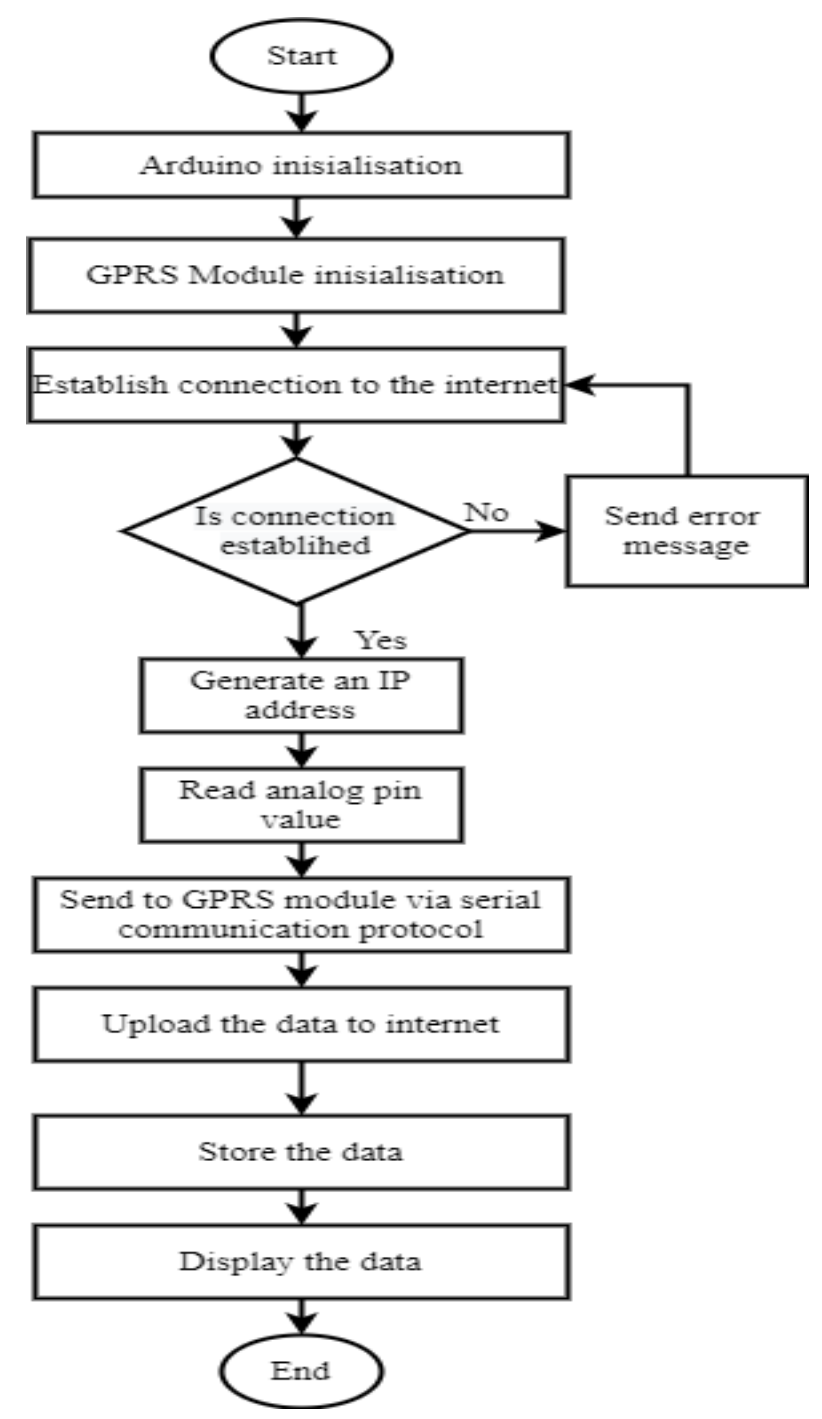

Figure 6. Overall algorithm for proposed system

\subsection{Web based monitoring application}

The real-time web monitoring connects to the database cloud using the internet. The web application processing of the data in real-time and record of all data and displays the position of the sensor by maps. In this web application for collect and store of data using MySQL Database and PHP language. The web application consists of a show for the information gathered from the sensor network. In this application, users can select which identity of sensors for shown visualization. The Architecture for the back end server separated into 2 main layers.

\subsubsection{Interface layer}

Covers PHP (hypertext Prepcessor) and Apache web server. In this work, interface layer can handle the function of the HTTP POST/GET instruction request from server level devices and web application clients. The sensor delivers to the cloud server using the PHP function (insert) and requests data from the database layer with insert and fetches function respectively (see Figure 4 in Layer 1).

\subsubsection{Database layer}

Our web application using the MySQL database server. The main function to store data received by the insert function and provide data in response to the fetch command (see Figure 4 in Layer 3 ).

The web application displays all the Ardupeat station on the web application. The local weather parameters accumulate at local ardupeat devices be sent to a database server, permit users to access real-time data from the ardupeat sensor. The user can access and view every time dynamically generated graph for 
changing local weather, such as temperature, humidity, soil temperature, soil moisture, rainfall, water level stored in the database server as shown in Figure 7. These systems, overall diagram of the system database and web application in Layer 3 and Layer 4 in Figure 4 as data synchronize to visualize the value data.

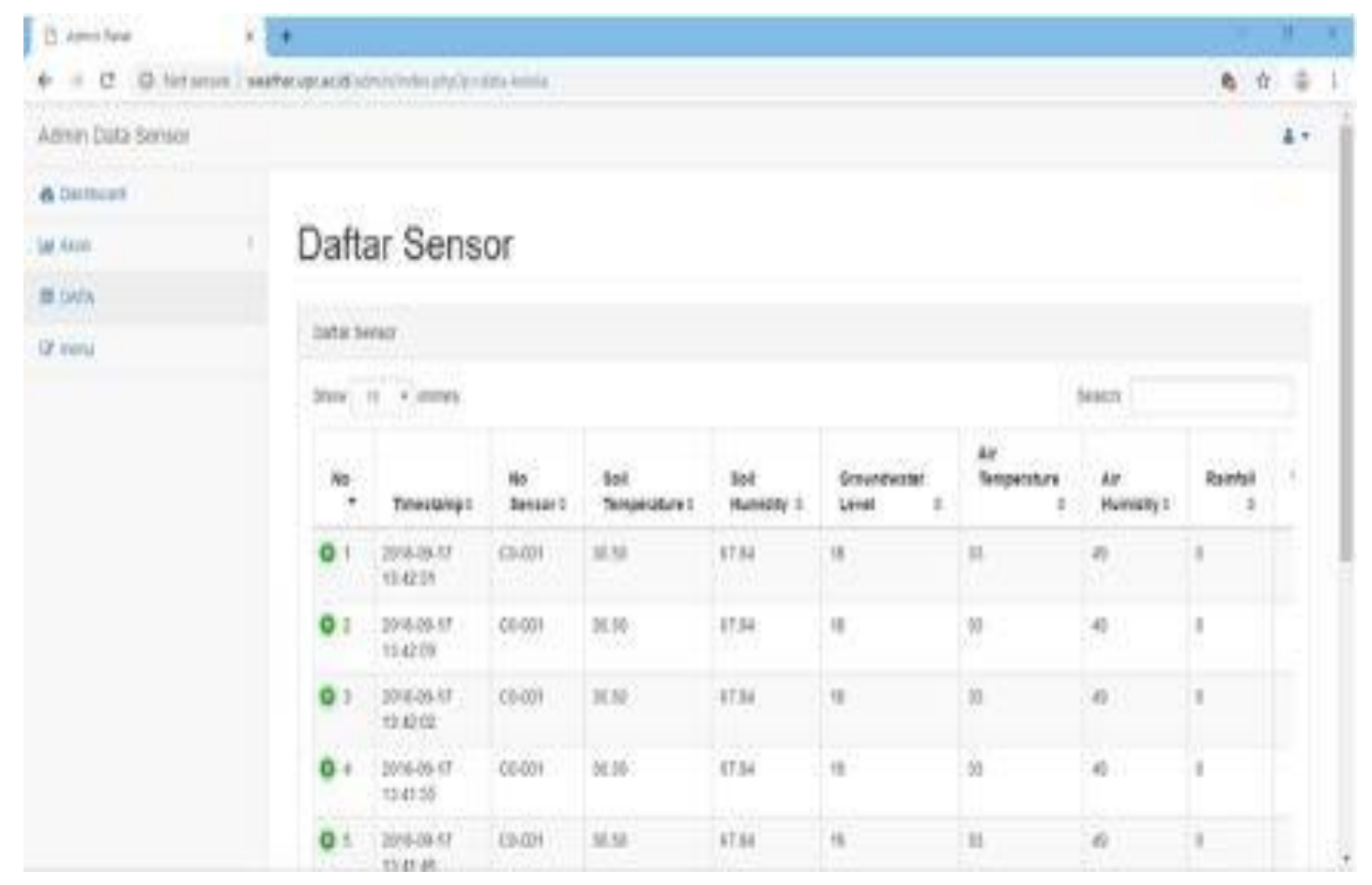

Figure 7. Dashboard for monitoring and weather data visualization

\section{RESULTS AND DISCUSSION}

In this work, we collect six parameters namely soil temperature, soil moisture, rainfall, air temperature, and groundwater level are record using the ardupeat sensor. Our device is connected to a realtime MySQL database for collect and store sensor value. In our experiment starts to get the sampling data from 28 September - 4 October 2019 in dry condition. The device sensor record and sends data every 15-minute using GPRS/3G network and collect into a database with different parameters.

\subsection{Measurement groundwater level}

In this work, every sensor send data local weather and water level with depth position. The key to control of peat fire is groundwater level and rainfall is very important as an alert for potential peat fire. The data groundwater level decrease toward 0.5 meters, this system provides alarm as an early warning system. The ultrasonic sensor prepares an operation range $25 \mathrm{~cm}$ to $4.5 \mathrm{~m}$ with resolution $0.5 \mathrm{~cm}$ measurement distance. The sensor ready to serve on an ultrasonic module that contains a transmitter, receiver, and control circuit. The ultrasonic sensor delivers a high-frequency propagation wave using frequency $40000 \mathrm{~Hz}$, and ultrasonic can the measure estimation of the echo received between signal transmissions from the pin trigger and receiving it back to the echo which forward determines the measurement distance to water.

The groundwater level measured distance using the ultrasound sensor and the groundwater level is to record into the web application as shown in Figure 7. We start to collect data on 1 October 2019, the water level condition is high around $28 \mathrm{Cm}$ in the peat after rainfall $28-29$ September 2019. We can see the relation with peat fire, the position of water level is $28 \mathrm{Cm}$ in Figure 1 in the category safe when the dangerous peat fire in-depth 0.5 meters water level. It occurs since at the time of sampling the water level, the peat soil was rain and the soil temperature be cold. Figure 8 shows there was a fluctuation in the water table level in the peatland it is correlated to rainfall conditions at this location during the observation period. In common conditions, the generic pattern of groundwater level dynamics is rather stable throughout the year. The water table level at this site rose in response to high rainfall intensities. In the local hydrology area is known to strongly influence peat decomposition. 

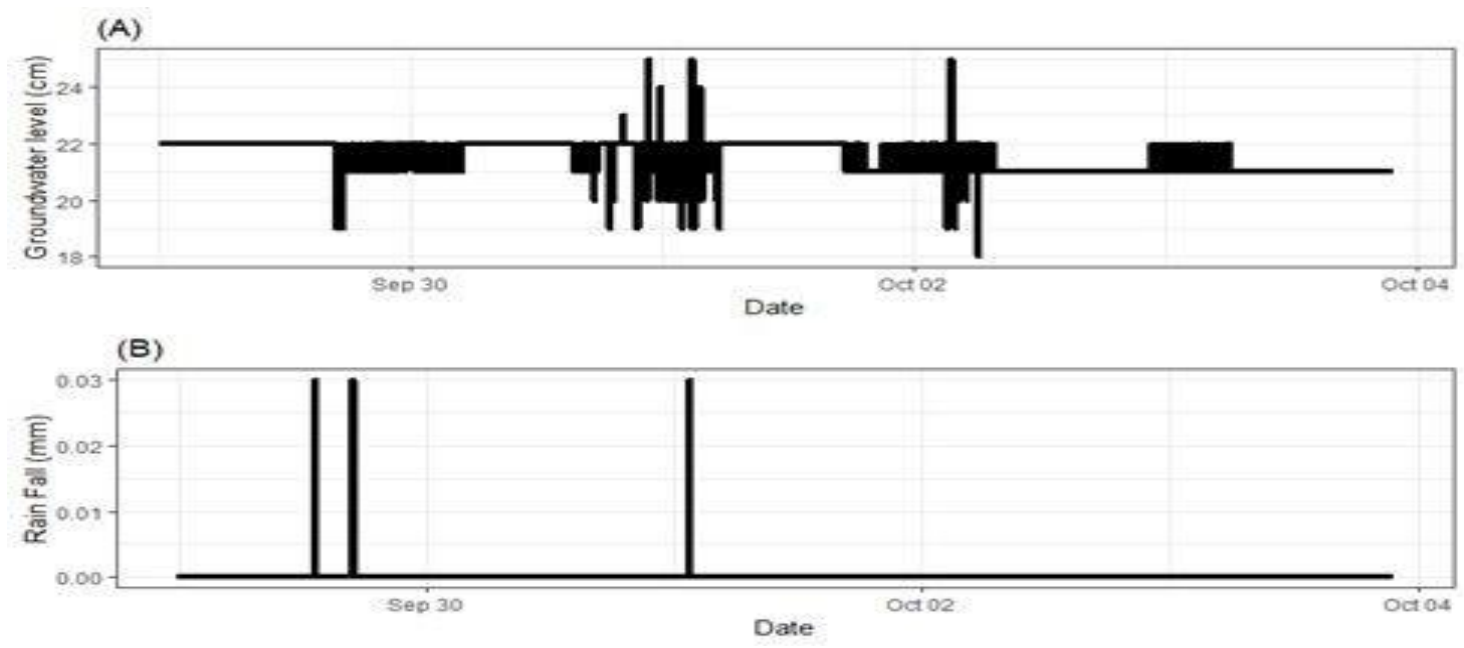

Figure 8. Groundwater level (A) and Rainfall (B)

\subsection{Measurement air temperature and humidity}

Figure 9 shows the condition air temperature and air humidity near the location of the peat. As shown in Figure 9 (A) the air temperature ranged from $24-40{ }^{\circ} \mathrm{C}$. The pattern of air temperature was relatively stable from September to October. In contrast, in early September the air temperature was quite high. Meanwhile, the pattern of air humidity in early September in decreased along with the increasing air temperature.
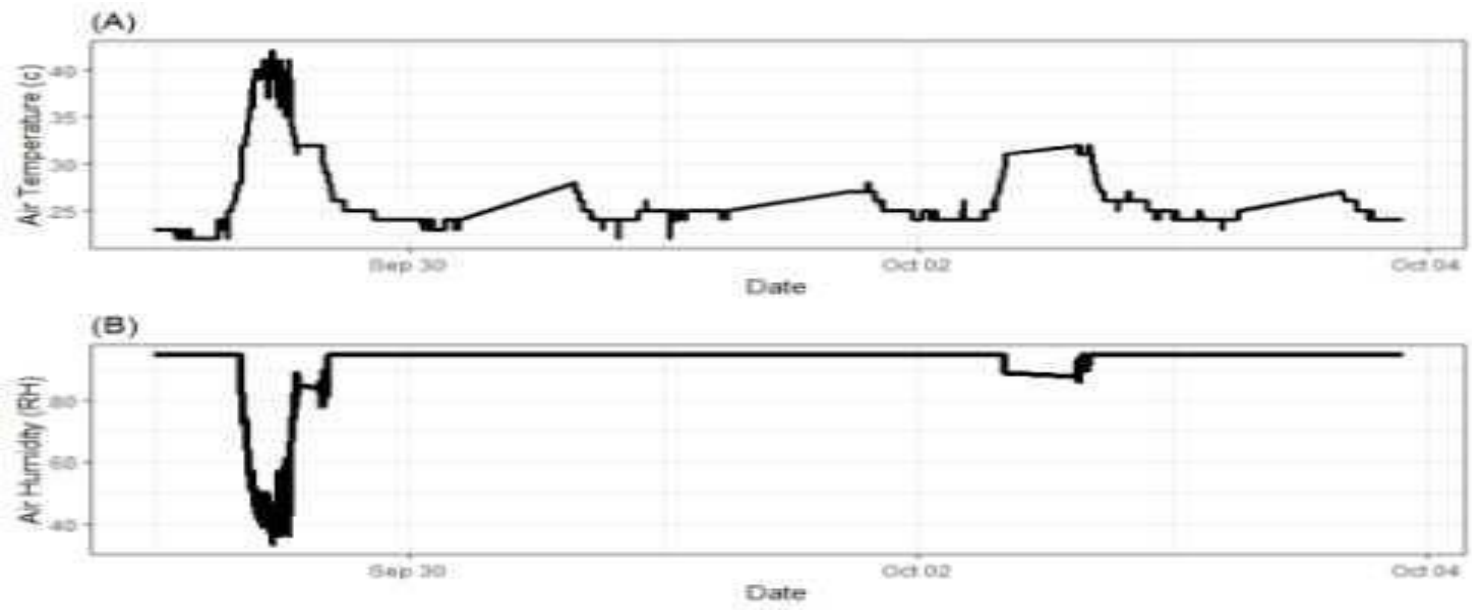

Figure 9. Air Temperature (A) and Air Humidity (B)

\subsection{Measurement soil temperature and humidity}

Figure 10 shows soil moisture and soil temperature. We found the fluctuation of soil moisture in different months, with ranged 7-26\%. Meanwhile, the soil temperature ranged from $26-34^{\circ} \mathrm{C}$. It means that environmental factors have an effect on it. The soil temperature and humidity are important in peat areas as a control of a weather environment. When the level of drought is high, the potential for the fire will be easier to trigger. 

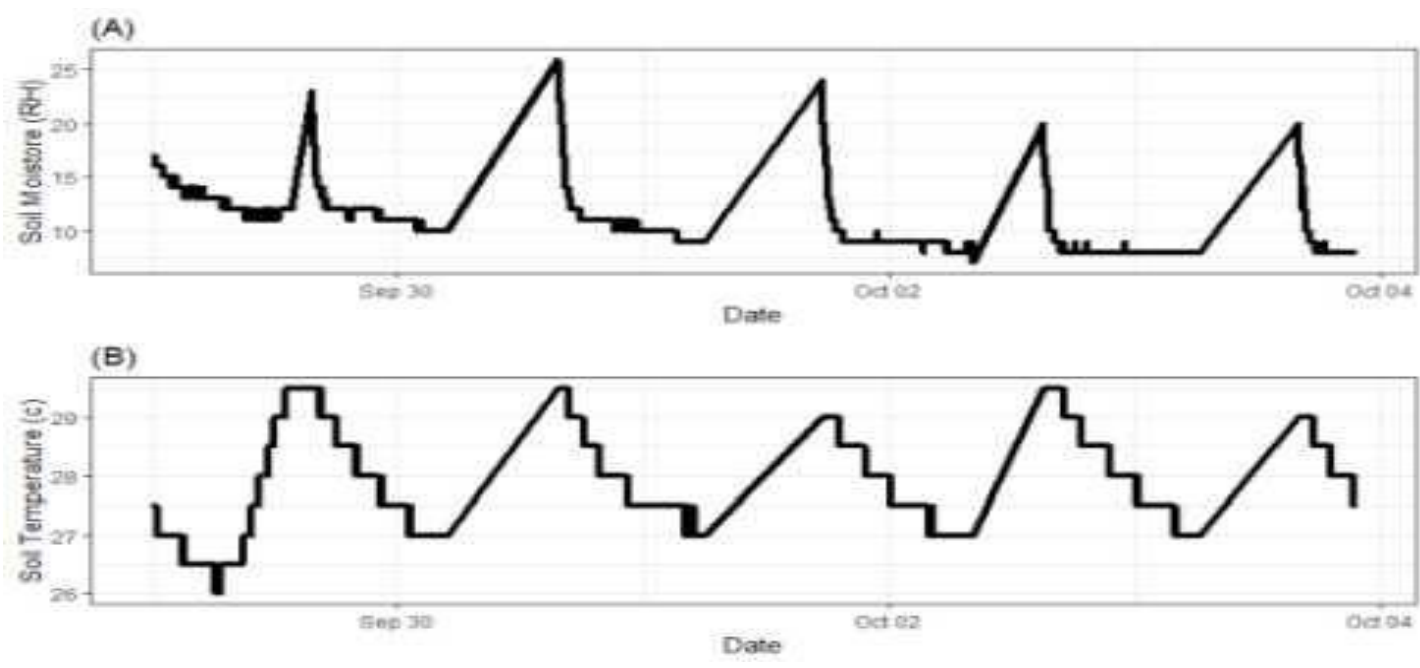

Figure 10. Soil Moistore (A) and Soil Temperature (B)

\section{CONCLUSION}

Our analyses of monitored environmental factors show that the real-time measurements by using this equipment many data were collected and could send to a computer-based system through an Arduino board. In this work, we can record and information display the local weather and condition of groundwater level by ardupeat sensor. These are prototype low costs especially monitoring groundwater level in the peatland environment. Our system built the development of low-cost sensors and open-source hardware refers to provide real-time groundwater level measurements at the peat. In this work, data results establish that with consistent calibration the prototype can maintain accurate results over an extended period of time. We conclude the prototype is useful for measure local climate in peat to recommend long-term groundwater level measurement.

\section{REFERENCES}

[1] J. H. M. Wösten, E. Clymans, S. E. Page, J. O. Rieley, and S. H. Limin, "Peat-water interrelationships in a tropical peatland ecosystem in Southeast Asia," Catena, vol. 73, no. 2, pp. 212-224, 2008, doi: 10.1016/j.catena.2007.07.010.

[2] G. E. Susilo, K. Yamamoto, and T. Imai, "Modeling Groundwater Level Fluctuation in the Tropical Peatland Areas under the Effect of El Nino," Procedia Environ. Sci., vol. 17, pp. 119-128, 2013, doi: 10.1016/j.proenv.2013.02.019.

[3] M. Taufik, A. A. Veldhuizen, J. H. M. Wösten, and H. A. J. van Lanen, "Exploration of the importance of physical properties of Indonesian peatlands to assess critical groundwater table depths, associated drought and fire hazard," Geoderma, vol. 347, no. February, pp. 160-169, 2019, doi: 10.1016/j.geoderma.2019.04.001.

[4] S. Sundari, T. Hirano, H. Yamada, K. Kusin, and S. Limin, "Effect Of Groundwater Level On Soil Respiration In Tropical Peat Swamp Forests," J. Agric. Meteorol., vol. 68, no. 2, pp. 121-134, 2012, doi: 10.2480/agrmet.68.2.6.

[5] N. C. Dadap, A. R. Cobb, A. M. Hoyt, C. F. Harvey, and A. G. Konings, "Satellite soil moisture observations predict burned area in Southeast Asian peatlands," Environ. Res. Lett., vol. 14, no. 9, 2019, doi: 10.1088/1748-9326/ab3891.

[6] E. I. PUTRA, "The effect of the precipitation pattern of the dry season on peat fire occurrence in the Mega Rice Project area, Central Kalimantan, Indonesia," Tropics, vol. 19, no. 4, pp. 145-156, 2011, doi: 10.3759/tropics.19.145.

[7] C. J. Watras et al., "Evaluation of wireless sensor networks (WSNs) for remote wetland monitoring: Design and initial results," Environ. Monit. Assess, vol. 186, no. 2, pp. 919-934, 2014, doi: 10.1007/s10661-013-3424-8.

[8] M. A. Nasirudin, U. N. Za'bah, and O. Sidek, "Fresh water real-time monitoring system based on wireless sensor network and GSM," 2011 IEEE Conf. Open Syst. ICOS 2011, no. September, pp. 354-357, 2011, doi: 10.1109/ICOS.2011.6079290.

[9] J. Gutierrez, J. F. Villa-Medina, A. Nieto-Garibay, and M. A. Porta-Gandara, "Automated irrigation system using a wireless sensor network and GPRS module,” IEEE Trans. Instrum. Meas., vol. 63, no. 1, pp. 166-176, 2014, doi: 10.1109/TIM.2013.2276487.

[10] Y. Shigenaga, H. Takahashi, R. Teguh, and W. Kencana, "Field Data Transmission System, SESAME-SATREPS, by Using Cell-phones Digital Telecommunications Network," Proc. Symp. Wildfire Carbon Manag. Peat For. Indonesia, no. May 2014, pp. 207-212, 2013, doi: DOI: 10.13140/RG.2.1.1627.0885.

[11] P. Jiang, H. Xia, Z. He, and Z. Wang, "Design of a water environment monitoring system based on wireless sensor networks," Sensors, vol. 9, no. 8, pp. 6411-6434, 2009, doi: 10.3390/s90806411.

[12] M. T. Lazarescu, "Design of a WSN platform for long-term environmental monitoring for IoT applications," IEEE J. Emerg. Sel. Top. Circuits Syst., vol. 3, no. 1, pp. 45-54, 2013, doi: 10.1109/JETCAS.2013.2243032.

[13] Y. N. Malek et al., "On the use of IoT and Big Data Technologies for Real-time Monitoring and Data Processing," Procedia Comput. Sci., vol. 113, pp. 429-434, 2017, doi: 10.1016/j.procs.2017.08.281. 
[14] C. D. Moreno-Moreno, M. Brox-Jiménez, A. A. Gersnoviez-Milla, M. Márquez-Moyano, M. A. Ortiz-López, and F. J. Quiles-Latorre, "Wireless Sensor Network for Sustainable Agriculture," Proceedings, vol. 2, no. 20, p. 1302, 2018, doi: 10.3390/proceedings2201302.

[15] A. Alkandari, "Wireless Sensor Network (WSN) for Water Monitoring System: Case Study of Kuwait Beaches," ... J. Digit. Inf. Wirel. ..., vol. 1, no. 4, pp. 709-717, 2011, [Online]. Available: http://sdiwc.net/digital-library/wirelesssensor-network-wsn-for-water-monitoring-system-case-study-of-kuwait-beaches.

[16] A. Glória, F. Cercas, and N. Souto, "Design and implementation of an IoT gateway to create smart environments," Procedia Comput. Sci., vol. 109, pp. 568-575, 2017, doi: 10.1016/j.procs.2017.05.343.

[17] J. Doshi, T. Patel, and S. K. Bharti, "Smart Fanning using IoT, a solution for optimally monitoring fanning conditions," Procedia Comput. Sci., vol. 160, pp. 746-751, 2019, doi: 10.1016/j.procs.2019.11.016.

[18] D. Wei, P. Liu, B. Lu, and Z. Guo, "Water quality automatic monitoring system based on GPRS data communications," Procedia Eng., vol. 28, no. 2011, pp. 840-843, 2012, doi: 10.1016/j.proeng.2012.01.820.

[19] Y. Wang, C. Qi, and H. Pan, "Design of remote monitoring system for aquaculture cages based on 3G networks and ARM-Android embedded system," Procedia Eng., vol. 29, pp. 79-83, 2012, doi: 10.1016/j.proeng.2011.12.672.

[20] E. M. Sroczan and A. Urbaniak, "Ultrasonic Flow Measure for Water and Wastewater Using Open Channel Weir," IFAC Proc. Vol., vol. 27, no. 3, pp. 135-140, 1994, doi: 10.1016/s1474-6670(17)46098-8.

[21] M. R. Laskar, R. Bhattacharjee, M. S. Giri, and P. Bhattacharya, "Weather Forecasting Using Arduino Based CubeSat," Procedia Comput. Sci., vol. 89, pp. 320-323, 2016, doi: 10.1016/j.procs.2016.06.078.

[22] B. Akhmetov and M. Aitimov, "Data collection and analysis using the mobile application for environmental monitoring," Procedia Comput. Sci., vol. 56, no. 1, pp. 532-537, 2015, doi: 10.1016/j.procs.2015.07.247.

[23] S. Kyi and A. Taparugssanagorn, "Wireless Sensing for a Solar Power System," Digit. Commun. Networks, vol. 6, no. 1, pp. 51-57, 2019, doi: 10.1016/j.dcan.2018.11.002.

[24] W. Priharti, A. F. K. Rosmawati, and I. P. D. Wibawa, "IoT based photovoltaic monitoring system application," $J$. Phys. Conf. Ser., vol. 1367, no. 1, 2019, doi: 10.1088/1742-6596/1367/1/012069.

[25] T. Kaur, J. Gambhir and S. Kumar, "Arduino based solar powered battery charging system for rural SHS," 2016 7th India International Conference on Power Electronics (IICPE), Patiala, 2016, pp. 1-5, doi: 10.1109/IICPE.2016.8079373. 